\title{
Estudo Exploratório da Conceitualização de Criatividade em Estudantes Universitários
}

\author{
Maria Alice d'Avila Becker \\ Pontifícia Universidade Católica do Rio Grande do Sul \\ Antonio Roazzi \\ Universidade Federal de Pernambuco \\ Milton José Penchel Madeira ${ }^{1}$ \\ Universidade do Vale do Rio dos Sinos \\ Isabel Arend \\ Universidade Autônoma de Madrid, Espanba \\ Daniela Schneider \\ Pontifícia Universidade Católica do Rio Grande do Sul \\ Lina Wainberg \\ Pontifícia Universidade Católica do Rio Grande do Sul \\ Bruno Campello de Soura \\ Universidade Federal de Pernambuco
}

\begin{abstract}
Resumo
A pesquisa visa a investigar a conceitualização que estudantes universitários têm sobre o que é a criatividade, por meio de análise multidimensional baseada na Teoria das Facetas. Inicialmente solicitou-se que os alunos expressem o que pensam com a evocação da palavra-estímulo criatividade, e a partir deste levantamento, selecionaram-se as 15 palavras mais freqüentemente evocadas. A seguir investigou-se a estrutura conceitual da palavra criatividade através da técnica não-verbal de classificação livre. Os resultados das inter-relações entre todas as variáveis foram analisados por meio da Análise da Estrutura de Similaridade produzindo uma estrutura tipo radex com o item criatividade na região central e cinco regiões distribuídas ao redor da mesma. Estas regiões identificaram cinco dimensões: Estética, Emoção, Gênese, Cognição e Volição. Os significados destas dimensões, em relação às principais questões abordadas pela literatura na área, são discutidos visando a melhor compreender a estrutura representacional do conceito de criatividade.

Palavras-chave: Criatividade; conceitos; categorização; classificação livre; Teoria das Facetas; análise multidimensional.
\end{abstract}

An Exploratory Study about how Creativity is conceived by University Students

\begin{abstract}
This study aimed to investigate how university students conceive the concept of creativity. We used a multidimensional analysis based on Facet Theory. Initially, we requested that students express what they think following the evocation of the stimulus word creativity; on the basis of this free association, 15 of the more frequently evoked words were selected. Next, we investigated the structure of the creativity concept of the 15 words through a free sort non-verbal task. The results of the interrelations among all the variables were analyzed by means of a Similarity Structure Analysis that produced a radex structure with item creativity in the central area and with five areas distributed around it. These areas identified five dimensions: Aesthetics, Emotion, Genesis, Cognition, and Volition. The meanings of these dimensions in relation to the major conceptual issues in the literature are discussed to seek better to understand the representational structure of the creativity concept. Keywords: Creativity; concepts; categorization; free sort; Facet Theory; multidimensional analysis.
\end{abstract}

Este estudo é o resultado de uma pesquisa que buscou tratar da compreensão do que no meio universitário é entendido por criatividade, utilizando uma metodologia com uma preocupação de tipo êmico em pesquisa sobre conceitos, visando uma maior aproximação e fidelidade aos dados da realidade.

A criatividade, apesar de ser uma palavra bastante utilizada no dia-a-dia, tem sido apontada na literatura especializada por uma grande variedade de definições.

\footnotetext{
${ }^{1}$ Endereço para correspondência: Curso de Psicologia Centro de Ciências da Saúde - Unisinos - Fone/Fax: (51)5908268. Fone: 32222911 E-mail dschneider2001@hotmail.com
}

Constata-se existir uma falta de clareza científica sobre sua conceitualização, justificando assim que se faça uma pesquisa sobre este foco. Esta indefinição parece servir para que no cotidiano utilizemos a palavra criatividade em uma variedade de situações, pois ela permite expressar uma amplitude de significados.

$\mathrm{Na}$ revisão da literatura abordam-se algumas das formas tradicionais de pesquisa em conceitos, bem como algumas das várias conceituações de criatividade. A inovação desse estudo refere-se à metodologia utilizada que permitiu vislumbrar o que, em nosso meio, se considera criatividade e seu resultado possibilita uma maior reflexão e planejamento sobre futuros caminhos de investigação neste tema. 


\section{A Importância do Estudo da Criatividade}

A Psicologia aumentou seu interesse no estudo da criatividade a partir da década de 1950, quando vários trabalhos começaram a abordar a questão do potencial humano para a auto-realização, levando a uma busca pelas condições e fatores que facilitariam a sua expressão e novas soluções para os problemas enfrentados pela humanidade (Alencar, 1996b). Entendemos que, segundo Alencar, um dos motivos desencadeadores desse súbito interesse foi o discurso de Guilford, ao assumir na época a presidência da American Psychological Association, enfatizando a falta de estudos sobre esse tema. Essas conjunturas levaram diferentes componentes que se supunham favorecedores da criatividade a se tornarem objeto de inúmeras pesquisas realizadas sob os mais diversos enfoques teóricos. Desde então, estuda-se como ocorre o processo criativo, o produto criativo resultante, o perfil de personalidade do indivíduo criativo e as características do ambiente sócio-econômico, educacional e familiar que permitem ou mesmo deflagram a eclosão da criatividade. Wechsler (1999), fez um recente estudo sobre como as abordagens comportamental, gestáltica, psicanalítica, humanista e cognitivista contribuem para a avaliação e a compreensão da criatividade.

Roazzi e Souza (1997) referem-se ao fato de que o estudo da criatividade está agora em seu ponto máximo, com instituições internacionais de ensino e de pesquisa investindo enormes recursos financeiros nos estudos sobre a natureza do processo criativo. Muitas empresas nos EUA e na Europa estão utilizando testes de criatividade no processo de seleção de seus funcionários e empregando programas de desenvolvimento do potencial criativo como forma de aumentar a produtividade dos seus empregados e suas organizações. Numa época em que o constante desenvolvimento e a aplicação de novas tecnologias são a força motriz, faz-se necessário um fluxo contínuo de idéias originais. $\mathrm{Na}$ opinião destes autores, a criatividade parece ser o fator cognitivo humano que pode satisfazer às exigências de uma sociedade que cada vez mais requer soluções eficientes para os novos problemas que surgem a todo o momento.

\section{Criatividade: Um Conceito Multifacetado}

A criatividade é um conceito complexo, de difícil definição, que se condiciona segundo o âmbito de aplicação e que pode ser abordado a partir de inúmeras perspectivas diferentes. Um exemplo da variação do significado do termo "criatividade" em função da área de atuação é dado por Vervalin (1975). Segundo esse autor há criatividade na música, literatura e artes, que são as áreas onde tradicionalmente se aplica o conceito, mas também existe a criatividade científica, a criatividade tecnológica e diversas outras formas de pensamento original. Já as instâncias, onde diferentes abordagens são utilizadas para se estudar a criatividade, conseguem ser tão ou mais variadas do que as múltiplas esferas de aplicação da palavra.

Para Gardner (1996), a análise da criatividade em todas as suas formas está além da competência de uma única disciplina, sendo necessários diferentes níveis de análise para se entender o fenômeno. A sua premissa básica sobre esse assunto é a de que um indivíduo não pode ser criativo num plano abstrato puro, descontextualizado, sendo a sua criatividade sempre expressa através de domínios ou disciplinas específicos. Assim, ele estabelece a necessidade de se considerar o talento individual, o domínio/disciplina em que o indivíduo está atuando e o campo que julga a qualidade e utilidade dos produtos desenvolvidos. Sob esse ponto de vista, a criatividade não pertence a nenhum desses elementos isolados, sendo melhor compreendida como o resultado de todo o conjunto. Portanto, para Gardner, a criatividade não está somente na idéia, no processo ou na habilidade do artista, nem no domínio de prática e tampouco no grupo de juízes, mas sim numa interação entre todas essas dimensões.

Eysenck (1999) sugere a existência de três conjuntos de variáveis que fazem parte do que se considera criatividade: variáveis cognitivas (inteligência, conhecimento, habilidades técnicas, talentos especiais), variáveis ambientais (fatores político-religiosos, fatores culturais, fatores sócio-econômicos, fatores educacionais) e variáveis de personalidade (motivação interna, confiança, não-conformismo, criatividade traço). A idéia é a de que todo este elenco de fatores permite a criatividade enquanto uma realização.

A perspectiva clínica oferece uma alternativa para lidar com o problema de uma definição vaga ou imprecisa. Afinal, quando se busca fazer um diagnóstico em psicopatologia, é freqüente se esbarrar na dificuldade em se classificar num quadro clínico específico o conjunto de sintomas apresentado por um paciente. Handler e Potash (1999) chamam a atenção para o fato de que muitos profissionais da área de saúde, tais como psicólogos e médicos, tradicionalmente têm lidado com a questão definindo a saúde mental ou física como sendo a ausência de patologia. Assim, tem-se como orientação o DSM IV (APA, 1995), um sistema dimensional que classifica condições clinicas quantificando atributos com distribuição contínua e/ou sem limites claros. Mas esses sistemas dimensionais também apresentam suas limitações. Handler e Potash apontam que, em comparação com as categorias de patologia descritas em inúmeros artigos, pouquíssima atenção tem sido dada para a criatividade, para o otimismo e para a capacidade de brincar e amar. 
As variáveis que são observadas nos testes referem-se a padrões de desadaptação e a outras patologias, negligenciando as abordagens que enfoquem o que está saudável nas pessoas.

De acordo com Roazzi e Souza (1997), o estudo da criatividade apresenta dois desafios fundamentais: (1) o estabelecimento de uma definição precisa e satisfatória do termo "criatividade" e (2) a criação de uma forma de se obter uma medição útil e confiável de uma grandeza definida. De fato, "Taylor (1959, citado em Alencar, 1996b) encontrou mais de cem definições distintas - e, às vezes, até mesmo conflitantes - para o termo, o que interpretou como sendo uma conseqüência do fato de que a criatividade, assim como a inteligência, é um construto complexo e difuso que envolve muitas dimensões e facetas" (p.306). Alencar opina que estamos em um estágio inicial sobre o conhecimento deste assunto e muitos questionamentos sobre a avaliação e medidas de criatividade ainda estão sem resposta ou com respostas não totalmente satisfatórias.

Diante dessa conjuntura teórica do estudo da criatividade, ou seja, com a existência de uma enorme amplitude de abordagens, definições e formas de avaliação sobre o tema, pensamos que devemos inicialmente compreender a noção do que é um conceito, o que nos proporcionará um maior entendimento sobre o tema.

\section{Sistemas Conceituais e Categorias}

O estudo dos conceitos é, segundo Madeira (1987), uma área que vem sendo cada vez mais valorizada na Psicologia Cognitiva como uma forma de retornar o projeto inicial de Wundt do final do Século XIX: ser uma ciência da vida mental. Afinal, sempre houve interesse da parte dos psicólogos em compreender como se organiza a representação mental que o psiquismo elabora a respeito do mundo que o circunda (Costermans, 1981).

A Psicologia Cognitiva considera "conceito" como sendo a construção de uma representação mental através de uma estrutura semântica expressa via código verbal e/ ou imagem simbólica dos objetos e fenômenos. Portanto, a formação de um conceito é uma elaboração psíquica, ou seja, uma representação abstrata que permite a categorização de pessoas e/ou coisas e o seu reagrupamento em função de múltiplos atributos, facilitando a compreensão do mundo e a interação com ele.

A partir dessa idéia básica, compreendem-se os conceitos como uma forma de organizar as representações mentais do mundo externo, um meio de realizar as combinações de atributos necessárias para colocar cada conceito como o representante de uma categoria. Assim, quanto mais e melhor algo do mundo externo é representado num conceito, mais representante da sua categoria esse conceito será. Além disso, cada conceito é uma combinação das propriedades do objeto ou objetos que representam, o que permite o estabelecimento e a caracterização de relações entre dois ou mais conceitos numa teia hierárquica que define verdadeiros "parentescos". E sempre que dois ou mais objetos ou eventos distintos são tratados com equivalência, tal como serem designados todos com o mesmo nome, existe uma categoria. É preciso lembrar, contudo, que independentemente de um léxico em comum, as pessoas não tratam os diversos estímulos como iguais, devido às suas diferentes experiências passadas.

$\mathrm{Na}$ pesquisa sobre conceitos e categorias, em geral, estas últimas são consideradas como um reagrupamento de objetos concretos que ilustram os primeiros. Já o conceito, ao contrário da categoria, é uma representação mental abstrata que não se refere a nenhum objeto concreto em particular. Tal distinção, contudo, não está bem clara na literatura (Fortin \& Rousseau, 1992).

$\mathrm{Na}$ vida cotidiana, não se necessita conceituar o mundo ao redor de si com rigidez, pois, sabe-se que os conceitos podem ser mais ou menos globalizantes e, conseqüentemente, muitas vezes permite-se que eles permaneçam com sentido vago. Isto não significa que o próprio mundo seja desprovido de ordem, de modo que a tendência é a de sempre se estar conceituando estímulos e experiências novas. Diferente da imagem, a qual representa um objeto de forma concreta através de suas características físicas organolépticas, os conceitos são representados por palavras e, portanto, são abstratos.

\section{As Principais Pesquisas sobre Conceitos}

As pesquisas iniciais sobre a formação de conceitos utilizaram conceitos precisos descritos por regras lógicas bem definidas. Neste contexto, entende-se uma regra lógica como sendo a ligação que une os valores de duas dimensões, sendo mais usadas a regra conjuntiva (e), disjuntiva (ou), e condicional (se-então). Assim, um conceito é definido por uma característica ou uma combinação de características feitas através de certas regras de combinação (Fortin \& Rousseau, 1992). Existem, contudo, outras visões alternativas.

Wittgenstein (1953, citado em Pozo, 1998) rejeita a noção de que todos exemplares de um conceito têm uma série de atributos em comuns, como defende a teoria clássica, e propõe que aquilo que une os exemplares dentro de um mesmo conceito é a semelhança familiar entre os mesmos.

Madeira (1987) acrescenta que as categorias podem ser estudadas sob o enfoque artificial ou natural. As categorias naturais são aquelas determinadas pelas culturas ou pelo próprio sujeito através do contato cotidiano com 
os objetos do mundo natural. Elas são organizadas hierarquicamente em taxonomias e definidas mais em relação a sua dimensão contínua do que a sua dimensão descontínua. Largura e cor, por exemplo, são dimensões contínuas. Em uma categoria natural, os membros não são todos iguais, havendo alguns que se mostram mais típicos do que outros da mesma categoria, além das características não serem perfeitamente independentes umas das outras, como nas categorias artificiais.

Os estudos de Rosch (1975) sobre as categorias naturais permitiram conhecer a sua estrutura hierárquica, um complexo dentro do qual conjuntos de categorias são organizados de modo a formar taxonomias, ou seja, sistemas onde os elementos são ligados uns aos outros por inclusão de classes. Quanto mais uma categoria apresenta um nível de inclusão elevado no sistema taxonômico, mais a categoria inclui outras categorias, e igualmente, mais elevado é o nível de abstração da categoria. Essa noção de abstração de uma categoria definida segundo a quantidade de categorias que ela pode incluir corresponde à experiência subjetiva.

Mervis e Rosch (1981) levantaram a hipótese de que um membro de uma categoria é percebido como mais típico se ele possui um número maior de atributos comuns com os outros membros da categoria à qual ele pertence ("semelhança familiar"). De acordo com estes autores, para a maioria das categorias naturais forma-se um protótipo a partir do qual se categorizam os objetos encontrados no dia-a-dia. Tal protótipo é uma representação abstrata que possui os valores médios das características, definindo a sua pertinência a uma dada categoria.

Existe um modelo que ajuda a definir as categorias conceituais e as relações entre elas chamado de "modelo clássico", elaborado por Collins e Quillian (1969). Esses autores propõem que a melhor forma de representar as categorias é hierarquizando-as e examinando suas propriedades, tendo em vista que, segundo eles, as pessoas formam as suas representações mentais de forma hierárquica. Desse modo, existem desde os pontos mais gerais e abstratos (como os conceitos em si) até os pontos mais subordinados (que são ou estão mais dependentes do conceito geral). O modelo de rede de Collins e Quillian supõe que a informação semântica de que as pessoas dispõem ficam armazenadas numa estrutura de rede hierarquizada e logicamente ordenada.

Outro modelo bastante conhecido é o da comparação de características, proposto por Rips, Shoben e Smith (1973, citado por Pozo, 1998). Nele, para responder a uma verificação de enunciados semânticos um sujeito deve efetuar comparações. A idéia básica é a de que existe um ponto limítrofe além do qual duas coisas podem parecer tão diferentes que se pode rapidamente identificar tal diferença. Esse ponto é pessoal, ou seja, para algumas pessoas a diferença é grande, enquanto que para outras não é. Esse modelo fundamenta-se na noção de similaridade semântica, com a verificação devendo ser feita pela freqüência de produção da categoria, isto é, a freqüência com que as pessoas nomeiam uma categoria a partir de um conceito dado.

Nos estudos realizados, constatou-se que os conceitos podem estar mais próximos ou mais distantes, e que esta distância conceitual é variável (Fortin \& Rousseau, 1992).

Também existem modelos onde os exemplares não parecem ser típicos nem atípicos, sendo a sua classificação dada em termos de limites difusos, ou seja, categorias maldefinidas ou categorização difusa. Isso significa que um objeto pode ter a aparência de pertencer a uma categoria, porém pertencer a outra, pertencer as duas ou não pertencer a nenhuma. É isso o que gera a sua "difusibilidade" quanto aos limites de categorização (Madeira, 1989).

Eleanor Roch $(1973,1975$, citado por Madeira, 1987) contribuiu significativamente para a Psicologia Cognitiva quando anunciou que existem categorias difusas, uma alternativa à categoria em si. Dentro dessa perspectiva, o termo "cadeira", por exemplo, tem certas propriedades funcionais que formam uma parte específica dessa categoria. Rosch realizou trabalhos experimentais para observar os efeitos da tipicalidade, isto é, do conceito que representa o objeto como sendo aquele que reúne todas as principais características que o tornam representante de uma categoria (um caráter de tipicalidade). As pesquisas de Rosch sobre as categorias naturais nos meados da década de 70 permitiram uma sistematização deste campo da Psicologia Cognitiva, sobretudo no que concerne à definição das categorias mal-delimitadas, substituindo, assim, o ponto de vista clássico no estudo dos conceitos mentais.

Desde as pesquisas de Bruner (1956, citado por Mervis \& Rosch, 1981), as investigações sobre conceitos e categorias têm considerado os seguintes problemas:

1. A arbitrariedade das categorias, isto é, se existe uma razão subjacente à divisão arbitrária para se começar uma categoria dividindo os objetos em categorias;

2. A equivalência dos membros de uma categoria, ou seja, se todos os membros representam igualmente a categoria;

3. A determinação da representação e do relacionamento dos limites das categorias;

4. A natureza da abstração exigida, ou seja, se apenas a memória de exemplares individuais é necessária ou se as abstrações de ordem elevada do conhecimento geral estão além das categorias individuais;

5. Se a decomposição das categorias em elementos é qualitativa; 
6. Quais são as características dos atributos e qual a sua natureza.

Como resposta a todos estes questionamentos, as pesquisas realizadas estabeleceram o seguinte: (1) as categorias são estruturadas internamente por representatividade; (2) os limites não são necessariamente precisos; (3) existe uma relação próxima entre os grupos de atributos e a estrutura e formação de categorias.

\section{Pesquisando o Conceito de Criatividade}

Uma forma interessante de estudar o conceito de criatividade é através da Teoria das Facetas de Guttman $(1954,1959,1965)$, uma técnica utilizada em pesquisas na área de estrutura da inteligência, ciências sociais e comportamento. Para Dancer (1990), na discussão da validade de um construto sobre uma medida comportamental, os textos sobre psicometria enfatizam que os itens referentes a tal medida devem ter clara a definição daquilo que está sendo medido. Isso significa, entre outras coisas, que os itens devem ser suficientemente variados e amplos como para cobrir todos os aspectos relevantes do conteúdo do domínio em questão. $\mathrm{Na}$ pesquisa comportamental, Guttman (1965) sugere que nossa percepção ou pensamento sobre uma coleção de fatores pode levar à identificação de variáveis perceptuais ou semânticas, chamadas de facetas, as quais caracterizam os componentes básicos de variáveis consideradas relevantes. A coleção de todas essas facetas pode ser usada para formular a definição de um construto, porque, presumivelmente cada faceta reflete um componente essencial do universo de variáveis desse construto.

Levando em consideração a discussão anterior e tendo em vista que a criatividade, apesar de muito pesquisada e discutida, ainda é um construto de difícil conceitualização, planejou-se um estudo com a finalidade de investigar como estudantes de diferentes áreas do conhecimento definem o termo "criatividade". Para se ter conhecimento da representação da palavra a ser estudada, a investigação foi realizada usando-se a evocação de atributos, o que constitui uma nova perspectiva de estudo no que se refere às pesquisas anteriores. $\mathrm{O}$ objetivo foi o de averiguar a conceitualização da palavra "criatividade" em estudantes universitários gaúchos.

A escolha da metodologia de pesquisa utilizada no estudo exploratório foi influenciada, em grande parte, pelas críticas freqüentes às inúmeras definições de criatividade existentes e também pela falta de uma teoria explicativa geral. Devido a isso, optou-se por fazer uso de métodos de análise multidimensional que expressassem com a maior fidelidade possível o pensamento dos pesquisados, evitando o tipo de viés que um questionário preparado com conceitos retirados da literatura poderia induzir. De acordo com Roazzi (1995), o uso de análises multidimensionais não-métricas baseia-se em processos de categorização, permitindo que se conheça a emergência de sistemas conceituais e sua relação com o processo de categorização, já que este procedimento possibilita que se convertam distâncias e similaridades psicológicas em distâncias euclidianas.

\section{Participantes}

\section{Método}

Inicialmente, participaram do estudo 70 estudantes universitários dos cursos de graduação em Educação, Jornalismo e Psicologia. Em um segundo momento, participaram os mesmos estudantes dos cursos de Psicologia e Educação em um total de 42 alunos, pois os de Jornalismo já estavam em férias.

\section{Instrumentos e Procedimentos}

\section{Etapas da Investigação:}

A coleta de dados foi realizada coletivamente em cada curso, em duas fases distintas, começando com uma associação livre e terminando com uma classificação livre:

Primeira Fase - Associação Livre: Foi levantada a representação da palavra criatividade entre os alunos dos três cursos citados. Especificamente, foi solicitado aos sujeitos que, durante um minuto, escrevessem livremente o que se passava em suas mentes com a evocação da palavra-estímulo "criatividade". No levantamento das respostas produzidas, foram selecionados os dezenove itens mais freqüentemente evocados pelos estudantes.

Segunda Fase - Classificação Livre: Foi solicitado aos mesmos estudantes que classificassem os itens mais freqüentemente evocados na primeira fase, junto com o próprio termo "criatividade", de acordo com o grau de similaridade entre as palavras. Os participantes tinham a liberdade de construir quantas categorias fossem necessárias, podendo cada categoria conter as palavras que se desejasse, mas não podendo utilizar duas vezes a mesma palavra. Todas as palavras foram escritas em ordem alfabética no quadro negro, tanto para facilitar a visão, quanto para não influir na formação das categorias. Todos foram instruídos a utilizar o tempo que fosse necessário, e a construir as categorias exatamente como desejassem. Também foi informado que eles poderiam reajustar e modificar as categorias produzidas até que ficassem satisfeitos com elas. Logo que os estudantes terminaram a classificação, pediu-se que verificassem se estavam satisfeitos com a colocação das palavras em cada grupo, permitindo que fizessem as últimas modificações que considerassem necessárias.

Ao final das duas fases de coleta de dados, a cada sujeito foi pedido ainda que escrevesse o motivo que $o$ 
levou a formar cada grupo, isto é, o critério norteador da sua classificação.

\section{Técnica de Análise}

Para se observar as inter-relações entre todas as variáveis estudadas, os dados foram submetidos a tratamento estatístico do tipo multidimensional nãométrico, usando a técnica conhecida como "Análise da Estrutura de Similaridade" (em inglês, Similarity Structure Analysis, SSA; Borg \& Lingoes, 1987; para maiores detalhes ver Roazzi, 1995). Visto que os dados coletados eram de natureza nominal, a partir das classificações dos sujeitos foi produzida uma matriz de associação de tipo triangular entre todos os dezenove itens; mais especificamente, as células desta matriz apresentavam as freqüências de classificação de cada item com cada um de todos os outros itens. É a partir desta matriz que a análise SSA foi computada.

A partir deste procedimento de análise, é possível explorar de maneira mais detalhada a estrutura conceitual da palavra estímulo criatividade, revelando relações internas e regras nas dimensões ou facetas observadas, permitindo, assim, verificação empírica de hipóteses formuladas através da correspondência entre hipótese e a definição conceitual das observações.

Roazzi (1995) sugere ainda que, em seguida, se interprete os resultados através da Teoria das Facetas dividindo-se o processo de investigação em três componentes inter-relacionados:

1. O estabelecimento de um sistema definidor dos aspectos e variáveis sendo estudados (facetas);

2. A formulação das relações hipotetizadas entre esse sistema definidor e a estrutura das observações empíricas;

3. O estabelecimento de uma base racional para estas hipóteses.

Roazzi (1995) considera que o método utilizado é adequado para se compreender a natureza qualitativa de dados coletados nas investigações durante suas fases exploratórias, e também na classificação livre. Isso é importante, tendo em vista que os diferentes grupos de itens não implicam necessariamente numa diferença quantitativa (de mais para menos) entre os grupos. Esta forma de ver as coisas, junto com a conceitualização e observações de campo, enfatiza a inter-relação entre investigação empírica e construção teórica.

\section{Resultados}

\section{Fase 1}

Após a realização da primeira tarefa, as folhas de resposta foram recolhidas e todas as palavras que apareceram, inclusive aquelas que somente um dos sujeitos mencionou, foram tabuladas e digitadas em computador para a realização das análises estatísticas. Grande tempo e atenção foram dados a essa tarefa, considerando o grande número de palavras a serem compiladas, as diversas formas verbais distintas possíveis e as repetições com variações de conotação. Em certos casos, observou-se que algumas palavras, apesar de diferentes, queriam dizer a mesma coisa, de modo que foi decidido manter, nessas situações, a forma originalmente produzida pelo sujeito, evitando-se, assim, interpretações errôneas. Quando as palavras variavam entre singular e plural, verbo no infinitivo ou conjugado, por exemplo, elas foram agrupadas todas numa mesma categoria. O critério de escolha das palavras foi o de maior freqüência, pois, em nossa opinião, estas eram as mais significativas nesta população pesquisada. A partir desse procedimento de levantamento de dados, as dezenove palavras abaixo listadas foram obtidas:

alegria
arte
cor
criação
desenho
diferente
força
imaginação
inovar
inteligência
invenção
luz
música
original
pensamento
propaganda
trabalho
vontade

Fase 2

Nessa etapa, participaram os mesmos sujeitos dos cursos de Educação e de Psicologia, tendo em vista que os de Jornalismo já haviam entrado em férias. Assim, 42 sujeitos participaram desta fase. A partir dos grupos elaborados pelos participantes, foi levantado quantas vezes cada uma das palavras apareceram juntas, podendo-se, assim, obter as distâncias entre as palavras e entre elas e a palavra criatividade em função das freqüências com que elas ocorrem nos grupos.

Utilizou-se para análise dos dados a técnica do SSA, cujo princípio fundamental é o da expressão gráfica de correlações ou freqüência de co-ocorrências através da proximidade euclidiana num espaço dividido em regiões, onde cada região é uma faceta que contém os itens mais relacionados entre si. Cada item ou variável é representado graficamente por um ponto numa projeção bidimensional 
de um espaço geométrico com duas ou mais dimensões, mostrando regiões de contigüidade ou descontigüidade. A configuração espacial das palavras, mais o item criatividade, mostra facetas não-ordenadas e com uma partição espacial tipo radex, com cinco regiões ou facetas bem distintas, a saber: Estética, Emoção, Volição, Gênese e Cognição, todas relacionadas com a palavra-estímulo criatividade. Estas regiões e os itens que as compõem conforme se observa na Figura 1 serão discutidos a seguir.

\section{Discussão e Considerações Finais}

A presente pesquisa buscou investigar o modo como estudantes universitários de diferentes cursos conceituam a palavra "criatividade", a qual, como foi visto, é um construto multifacetado. O procedimento de análise

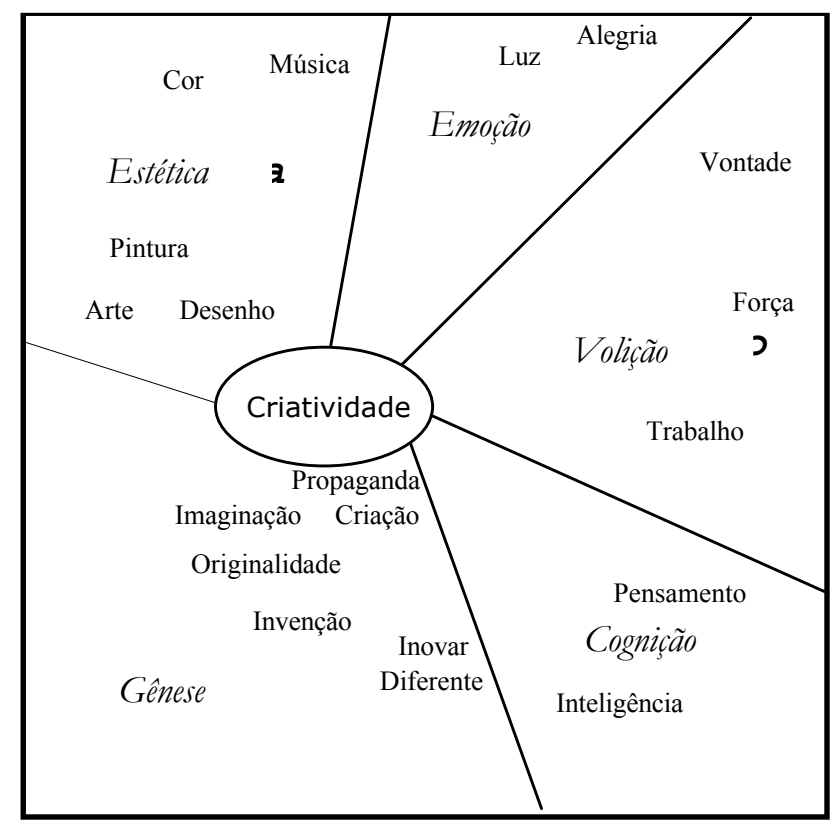

Figura 1. Projeção SSA da classificação livre (bidimensional)

escolhido foi o SSA, ideal para a análise de (dis) similaridades entre as definições dadas.

Observando a Figura 1 como um todo, nota-se que a palavra criatividade encontra-se no centro da projeção, e que as várias conceituações se espalham ao redor em diferentes distâncias, permitindo que se determine a representação e o relacionamento dos limites da categoria. Isso é importante, tendo em vista que, como observado anteriormente (Mervis \& Rosch, 1981), a pesquisa tem considerado que as categorias são estruturadas internamente por representatividade, ou seja, que os limites não são necessariamente precisos e que existe uma relação próxima entre os grupos de atributos e a estrutura/formação das categorias.
Em termos gerais, antes de descrever os itens que fazem parte das varias regiões é possível apontar que os que estão mais próximos do item central "criatividade" são "propaganda, criação, imaginação e desenho" significando que, para os estudantes, estas são as variáveis consideradas mais definidoras de criatividade. Já, "luz" e "alegria", no extremo oposto (lado direito superior), se distanciando bastante do centro, podem ser consideradas as menos relacionadas e menos representativas da criatividade. A distância espacial sugere uma falta de similaridade entre essas diferentes conceituações.

A primeira região que pode ser observada é aquela formada pelos itens localizados na parte superior da projeção. Localizadas logo acima da palavra "criatividade" encontram-se as palavras arte, pintura e desenho, as quais, junto com cor e música, mais ao alto, formam uma faceta que pode ser denominada Estética. Tudo isso faz referência à noção mais usual de criatividade, no sentido apontado por Vervalin (1975), ou seja, as artes em geral e atividades afins.

À direita da faceta Estética estão luz e alegria. Em princípio, luz seria associada a outras categorias mais sensoriais, como as que estão em Estética, mas o fato dela estar mais próxima de alegria do que de cor, desenho on pintura sugere que a palavra está sendo usada numa conotação emocional. Assim, faz sentido supor a existência de uma faceta que pode ser denominada Emoção, a qual contém luz e alegria.

Na parte inferior, no lado esquerdo da projeção, existe outro conjunto de palavras composto pelos itens propaganda, criação, imaginação e originalidade, que se encontram próximos do centro, juntamente com os itens invenção, inovare diferente. Uma denominação lógica para essa região seria Gênese, tendo em vista que todos os termos fazem referência a atividades de criação. Isso tende a confirmar o que a literatura menciona sobre criatividade e inovação, palavras que, por vezes, chegam a ser consideradas sinônimas. Inovação, embora faça parte de um mesmo domínio, é um termo mais comum na área organizacional.

"Inovar significa introduzir novidade, concebendose a inovação organizacional como o processo de introduzir, adotar e implementar uma nova idéia (processo, bem ou serviço) em uma organização em resposta a um problema percebido, transformando uma nova idéia em algo concreto" (Alencar, 1996a, p.15).

Ainda na parte inferior, mas do lado direito, se pode destacar uma outra faceta, que pode ser chamada de Cognição, formada por somente dois itens: pensamento $e$ inteligência. Esses itens se encontram bastantes distantes do centro, sugerindo serem variáveis que se relacionam 
pouco com a criatividade para os membros da amostra, não sendo muito definidoras do termo. No entanto, é preciso notar que, segundo Feldhusen e Goh (1995), o pensamento criativo é uma atividade cognitiva complexa, e as modernas concepções de criatividade são tão diversas e extensivas que uma definição de criatividade deve incluir atividades cognitivas relacionadas com a tomada de decisão, o pensamento crítico e a metacognição.

Ainda uma quinta região pode ser destacada do lado direito dando origem a uma faceta intitulável "Volição", composta dos itens trabalho, força, e vontade, que se encontram relativamente distantes do centro da projeção. Isto vem confirmar a idéia que a criatividade não aparece espontaneamente, sendo necessário esforço e trabalho para desenvolver um produto criativo.

Os itens das facetas "Volição" e "Cognição" podem ser considerados distantes, embora não dissociados do termo "criatividade" e, portanto, são menos represen-tativos da conceitualização da criatividade na amostra pesquisada.

As facetas indicadas no presente estudo podem ser pensadas como referentes a algumas das formulações de Eysenck (1999), para quem a criatividade inclui variáveis cognitivas (inteligência, conhecimento, habilidades técnicas, talentos especiais), variáveis ambientais (fatores políticoreligiosos, culturais, socioeconômicos, educacionais) e variáveis de personalidade (motivação interna, confiança, não-conformismo, criatividade traço), todas necessárias para que a realização criativa ocorra.

Também em conformidade com as facetas levantadas, é possível concordar com Gardner (1996), para quem a análise da criatividade em todas as suas formas está além da competência de uma única disciplina, sendo necessários vários níveis de análise para se chegar a tanto. Segundo ele, a criatividade se manifesta através de domínios ou disciplinas específicas, sendo necessário que se considere o talento individual, o domínio ou disciplina em que o indivíduo está trabalhando e o campo circundante que faz julgamentos acerca da qualidade de indivíduos e produtos.

Boden (1999) refere-se à idéia de que a definição da criatividade é impossível, questionando que se torna difícil saber quando uma idéia é considerada mais criativa do que outra. Desse modo, sugere que se explore a criatividade através dos espaços conceituais, que:

“(...) podem ser descritos em termos específicos, rigorosos e explícitos. As dimensões de um espaço conceitual são os princípios organizadores que unificam e dão estrutura a um dado domínio do pensamento. Em outras palavras, é o sistema gerativo que subjaz àquele domínio e define uma certa gama de possibilidades: movimentos de xadrez, estruturas moleculares ou melodias de jazz.
Os limites, contornos, trilhas e a estrutura de um espaço conceitual podem ser mapeados por representações mentais. Tais mapas mentais podem ser usados para explorar - e para mudar — os espaços em questão.(...) Algumas explorações somente mostram algo que não havíamos percebido explicitamente antes em relação à natureza de um determinado espaço conceitual (...) outras explorações, em contrapartida, nos mostram os limites do espaço, e talvez identifiquem pontos nos quais poderiam ser feitas mudanças em uma ou outra dimensão" (pp. 85-86).

Concluindo, a Teoria das Facetas (Borg, 1979, 1993; Dancer, 1990, Levy, 1993, citados em Cordeiro \& Roazzi, 1999), pode ser considerada uma meta-teoria, podendo ser utilizada para planejar o conteúdo de uma investigação e formular modelos de maneira cumulativa, integrando a teoria com o planejamento e a análise de dados. $\mathrm{O}$ tema "criatividade", como foi visto, está presente em muitos campos, possuindo uma complexa rede de variáveis que pertencem ao mesmo domínio de investigação. Como conseqüência desta concepção de criatividade, pode-se conhecer de forma mais abrangente quais são as conceituações que os estudantes dão para o termo e como se relacionam entre si. De acordo com Cordeiro e Roazzi, cada variável observada representa só um ponto no espaço ocupado pelo conceito investigado e, portanto, nunca poderá representar o conceito em sua plenitude/complexidade. Reunindo os itens das cinco facetas, observa-se que os mais próximos do centro são os que se referem à criação, com propaganda, criação, imaginação e originalidade da faceta "Gênese", bem como os itens desenho, pintura, e arte da faceta "Estética" e, portanto, são considerados os mais representativos de criatividade.

Enfim, a abordagem da Teoria das Facetas é uma forma alternativa para se analisar como a criatividade é compreendida, pois, permite visualizar as categorias e o modo como as pessoas agrupam em diferentes conceitos o que pensam ser criatividade.

\section{Referências}

Alencar, E. S. (1996a). A gerência da criatividade. São Paulo: Makron. Alencar, E. S. (1996b). A medida de criatividade. Em L. Pasquali (Org.), Teoria e métodos de medida em ciências do comportamento (pp. 305-318). Brasília: Ministério da Educação e do Desporto. Universidade de Brasília: INEP. Boden, M. A. (1999). O que é a criatividade? Em M. A. Boden (Org.), Dimensões da criatividade (pp. 81-123). Porto Alegre: Artes Médicas.

Borg, I. \& Lingoes, J. C. (1987). Multidimensional s imilarity structure analysis. New York: Springer.

Collins, A. M. \& Quillian, M. R. (1969). Retrieval time from semantic memory. Journal of Verbal Learning and Verbal Behavior, 8, 240-247.

Cordeiro, M. H. \& Roazzi, A. (1999). Avaliação multifacetada da leitura e da escrita: procurando superar a dicotomia quantidade versus qualidade em uma perspectiva muldimensional. Em S.M. Weschler \& R.S.L. Guzzo (Orgs.), Avaliação psicológica: Perspectiva internacional (pp.167-188). São Paulo: Casa do Psicólogo.

Psicologia: Reflexão e Crítica, 2001, 14(3), pp. 571-579 
Costermans, J. (1981). Psychologie Cognitive. Belgique: U.C.L.

Dancer, S. L. (1990). Introduction to facet theory and its applications. Applied Psychology: An International Review, 39, 365-377.

Eysenck, H. J. (1999). As formas de medir a criatividade. Em M. A. Boden (Org.), Dimensões da criatividade (pp. 203-244). Porto Alegre: Artes Médicas.

Feldhusen, J. F.\& Goh, B. E. (1995). Assessing and accessing creativity: an integrative review of theory, research, and development. Creativity Research Journal, 8(3), 231-247.

Fortin, C. \& Rousseau, R. (1992). Psychologie cognitive. Une approche de traitement de l'information. Quebec: Presse de l’Université du Québec TéleUniversité.

Gardner, H. (1996). Mentes que criam. Porto Alegre: Artes Médicas.

Guttman, L. (1954). An outline of some new methodology for social research. Public Opinion Quarterly, 18, 395-404.

Guttman, L. (1965). A general nonmetric technique for finding the smallest co-ordinate space for a configuration. Psychometrika, 33, 469-506.

Handler, L. \& Potash, H. M. (1999). Assessment of psychological health. Journal of Personality Assessment, 72, 181-184

Madeira, M. J. P. (1987). Processos cognitivos: O desenvolvimento de conceitos mentais. Psico, 14, 162-165.

Madeira, M. J. P. (1989). Processos cognitivos: Conceitos mal delimitados e classificação prototípica. Psico, 18, 19-27.
Manual Diagnóstico e Estatístico de Transtornos Mentais DSM- IV. (1995). Porto Alegre: Artes Médicas.

Mervis, C. B. \& Rosch, E. (1981). Categorization of natural objects. Annual Review Psychology, 32 , 89-115.

Pozo, J. I. (1998). Teorias cognitivas da aprendizagem. Porto Alegre: Artes Médicas. Roazzi, A. (1995). Categorização, formação de conceitos e processos de construção do mundo: procedimento de classificações múltiplas para o estudo de sistemas conceituais e sua forma de análise através de métodos multidimensionais. Cadernos de Psicologia, 1, 1-27.

Roazzi, A. \& Souza, B. C. (1997). Criatividade e desenvolvimento. Publicação interna do Curso de Pós-Graduação em Psicologia, Universidade Federal de Pernambuco, Recife/PE

Rosch, E. (1975). Cognitive representations of semantic categories. Journal of Experimental Psychology, 104, 192-223.

Vervalin, C. H. (1975). Que es la creatividad? Em G. A. Davis. \& J. A. Scott (Orgs.), Estrategias para la creatividad (pp. 19-23). Buenos Aires: Paidós.

Weschler S. M. (1999). Avaliação da criatividade: Um enfoque multidimensional. Em S. M. Weschler \& R. S. L. Guzzo (Orgs.), Avaliação psicológica: Perspectiva internacional (pp. 231-259). São Paulo: Casa do Psicólogo.

Recebido 17/05/2000

Revisado 08/12/2000

Aceite Final 07/02/2001

Sobre os autores

Maria Alice Becker é Psicóloga, Doutora pela PUCRS. Atualmente no Centro Universitário Luterano da Ulbra em Manaus, Amazonas.

Antonio Roazzi é Professor do Programa de Pós-Graduação em Psicologia da Universidade Federal de Pernambuco.

Milton José Penchel Madeira é Psicólogo, formado pela PUC do Rio/RJ em 1974, Doutor pela Universidade Católica de Louvain da Bélgica em 1989, Pós-Doutorado na Universidade de Montreal do Canadá em 1992/93 e atualmente é Professor do Curso de Psicologia da Universidade do Vale do Rio dos Sinos (UNISINOS), no Rio Grande do Sul.

Isabel Arend é Professora da Universidade Autônoma de Madrid, Espanha.

Daniela Schneider é Psicóloga formada pela PUCRS.

Lina Wainberg é Estudante de Psicologia da PUCRS.

Bruno Campello de Souza é Psicólogo e Doutorando de Programa de Pós-Graduação em Psicologia da Univeridade Federal de Pernambuco. 